\title{
Applying the WHO ICD-PM classification system to stillbirths in a major referral Centre in Northeast Nigeria: a retrospective analysis from 2010-2018
}

Eseoghene Dase ${ }^{1,2}$, Oghenebrume Wariri ${ }^{2,3,4^{*}}$ (D), Egwu Onuwabuchi ${ }^{1,2}$, Jacob A. K. Alhassan ${ }^{2,5}$, Iliya Jalo ${ }^{6,7}$, Nazeem Muhajarine ${ }^{5+}$, Uduak Okomo $^{3+}$ and Aliyu U. ElNafaty ${ }^{1,8+}$

\begin{abstract}
Background: Lack of a unified and comparable classification system to unravel the underlying causes of stillbirth hampers the development and implementation of targeted interventions to reduce the unacceptably high stillbirth rates (SBR) in sub-Saharan Africa. Our aim was to track the SBR and the predominant maternal and fetal causes of stillbirths using the WHO ICD-PM Classification system.

Methods: This was a retrospective observational study in a major referral centre in northeast Nigeria between 2010 and 2018. Specialist Obstetricians and Gynaecologists assigned causes of stillbirths after an extensive audit of available stillbirths' records. Cause of death was assigned via consensus using the ICD-PM classification system.

Results: There were 21,462 births between 1 January 2010 and 31 December 2018 in our study setting; of these, 1177 culminated in stillbirths with a total hospital SBR of 55 per 1000 births $(95 \%$ Cl: 52, 58). There were two peaks of stillbirths in 2012 [62 per 1000 births (95\% Cl: 53, 71)], and 2015 [65 per 1000 births (95\% Cl, 55, 76)]. Antepartum and intrapartum stillbirths were almost equally prevalent (48\% vs 52\%). Maternal medical and surgical conditions (M4) were the commonest (69.3\%) cause of antepartum stillbirths while complications of placenta, cord and membranes (M3) accounted for the majority (45.8\%) of intrapartum stillbirths and the trends were similar between 2010 and 2018. Antepartum and intrapartum fetal causes of stillbirths were mainly due to prematurity which is a disorder of fetal growth (A5 and 16).

Conclusions: Most causes of stillbirths in our setting are due to preventable causes and the trends have remained unabated between 2010 and 2018. Progress toward global SBR targets are off-track, requiring more interventions to halt and reduce the high SBR.
\end{abstract}

Keywords: Stillbirths, WHO ICD-PM, Gombe, Nigeria

\footnotetext{
* Correspondence: drwariri@gmail.com

${ }^{\dagger}$ Nazeem Muhajarine, Uduak Okomo and Aliyu U. ElNafaty are co-senior

authors.

${ }^{2}$ African Population and Health Policy Initiative, Gombe, Gombe State,

Nigeria

${ }^{3}$ Vaccines and Immunity Theme, Medical Research Council (MRC) Unit The

Gambia at The London School of Hygiene and Tropical Medicine, Banjul, The Gambia

Full list of author information is available at the end of the article
}

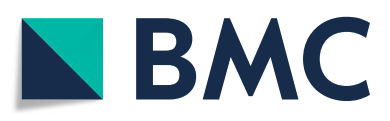

( The Author(s). 2020 Open Access This article is licensed under a Creative Commons Attribution 4.0 International License, which permits use, sharing, adaptation, distribution and reproduction in any medium or format, as long as you give appropriate credit to the original author(s) and the source, provide a link to the Creative Commons licence, and indicate if changes were made. The images or other third party material in this article are included in the article's Creative Commons licence, unless indicated otherwise in a credit line to the material. If material is not included in the article's Creative Commons licence and your intended use is not permitted by statutory regulation or exceeds the permitted use, you will need to obtain permission directly from the copyright holder. To view a copy of this licence, visit http://creativecommons.org/licenses/by/4.0/. The Creative Commons Public Domain Dedication waiver (http://creativecommons.org/publicdomain/zero/1.0/) applies to the data made available in this article, unless otherwise stated in a credit line to the data. 


\section{Background}

Globally, an estimated 2.6 million babies are stillborn (die in the last 3 months of pregnancy or during childbirth) with a Stillbirth rate (SBR) of 18.4 per 1000 births [1]. The overwhelming majority of these stillbirths occur in low- and middle-income countries (LMICS), particularly in Sub Saharan Africa and South Asia [2], and can be prevented through equitable and high-quality coverage of care for all women and newborns. Based on the Every Newborn Action Plan to improve newborn health and prevent stillbirths, a stillbirth target of 12 or less stillbirths per 1000 total births for all countries by 2030 was set, with a focus on addressing inequalities and the use of audit data to track and prevent stillbirths [3]. However, implementation will require that countries strengthen their ability to collect, compile, analyse, and report on data from the period of commencement, as well as maintain robust databases with constant data revolution [4].

In 2015, Nigeria was estimated to have the second highest stillbirth rate in the world (42.9/1000 births) [2]. National progress towards ending preventable stillbirths has been slow (annual rate of reduction approximately $1.3 \%$ ) in the context of weak health systems with limited infrastructure and populations faced with high out-ofpocket expenditures, poverty, inequality and societal unrest $[2,5]$. Complex humanitarian emergencies resulting from conflict in certain parts of the country have resulted in dramatic movements of people (including pregnant women and newborns), compromising access to health care [6]. This is most evident in northeast Nigeria where religious extremism and Boko Haram insurgency over the last decade have led to destruction of public utilities and socio-economic infrastructure with displacement of many communities and inequitable access to quality health services for vulnerable populations, notably women and children [6]. The direct consequences of this are marked regional disparities in coverage of essential health interventions and poor data reporting, thereby masking the true burden of maternal, newborn and child deaths including stillbirths.

Data on the number of deaths or the causes is essential to improve the quality of care, prevent future deaths, allocate resources, improve vital statistics, and reach global targets [7]. Registration of stillbirths and newborn deaths should be accompanied by programmatically relevant categorisation of the causes of death. The World Health Organization (WHO) recently adapted the International Classification of Diseases (ICD-10) for use in perinatal mortality (ICD-PM) [8]. The ICD-PM provides a standardised system for classifying perinatal mortality (including stillbirths) based on time of death (antepartum or intrapartum) into fetal and maternal causes thereby enabling comparisons within and between diverse settings and contexts [8]. The ICD-PM has been shown to work well using stillbirth data from the United Kingdom and South Africa $[9,10]$ and more recently in a multi-country setting in Kenya, Malawi, Sierra Leone and Zimbabwe [11]. To date, there is no such study that has used the ICD-PM system to classify stillbirths from Nigeria. We, therefore, applied the WHO ICD-PM retrospectively to determine the trends in SBR between 2010 and 2018 and the causes of stillbirths in a major tertiary referral health facility in northeast Nigeria.

\section{Methods}

\section{Study setting}

This was a retrospective study conducted at the Federal Teaching Hospital, Gombe (FTHG), in Gombe State, northeast Nigeria. Centrally located in this region, it shares borders with five other states - Adamawa, Bauchi, Bornu, Taraba, and Yobe (Fig. 1). Unlike its neighbouring states, Gombe is one of the states least affected by the armed conflict and insurgency in northeast Nigeria [12]. The estimated population of 3.3 million fluctuates due to movement of internally displaced persons from other states in the region [13]. The 450-bed capacity FTHG is a tertiary referral facility, receives patients from all five surrounding states. The hospital provides Comprehensive Obstetric care and is staffed with all cadres of the obstetric health workforce, including obstetricians/gynaecologists and midwives as well as anaesthetists and neonatologists. The average annual delivery rate for the hospital is about 2400 deliveries and the caesarean section rate is $27 \%$.

\section{Data collection}

We identified all stillbirths recorded in the hospital between 1st January 2010 and 31st December 2018 from delivery room, obstetric ward and theatre registers. Since stillbirth data are routinely documented in the maternal admission notes, we therefore retrieved the antenatal and admission records of mothers who had delivered a stillborn baby during the period under review. Using a pre-tested data extraction form, we collected the following data: maternal characteristics (age, parity, ethnicity and occupation); obstetric factors (antenatal attendance, gestational age at delivery, prior stillbirths, mode of delivery, obstetric and medical conditions); and fetal factors (birth weight, sex, congenital anomalies and type of stillbirth).

\section{Definition of terms and variables Stillbirth}

For international comparison, stillbirth was defined as any fetal death occurring prior to the complete 


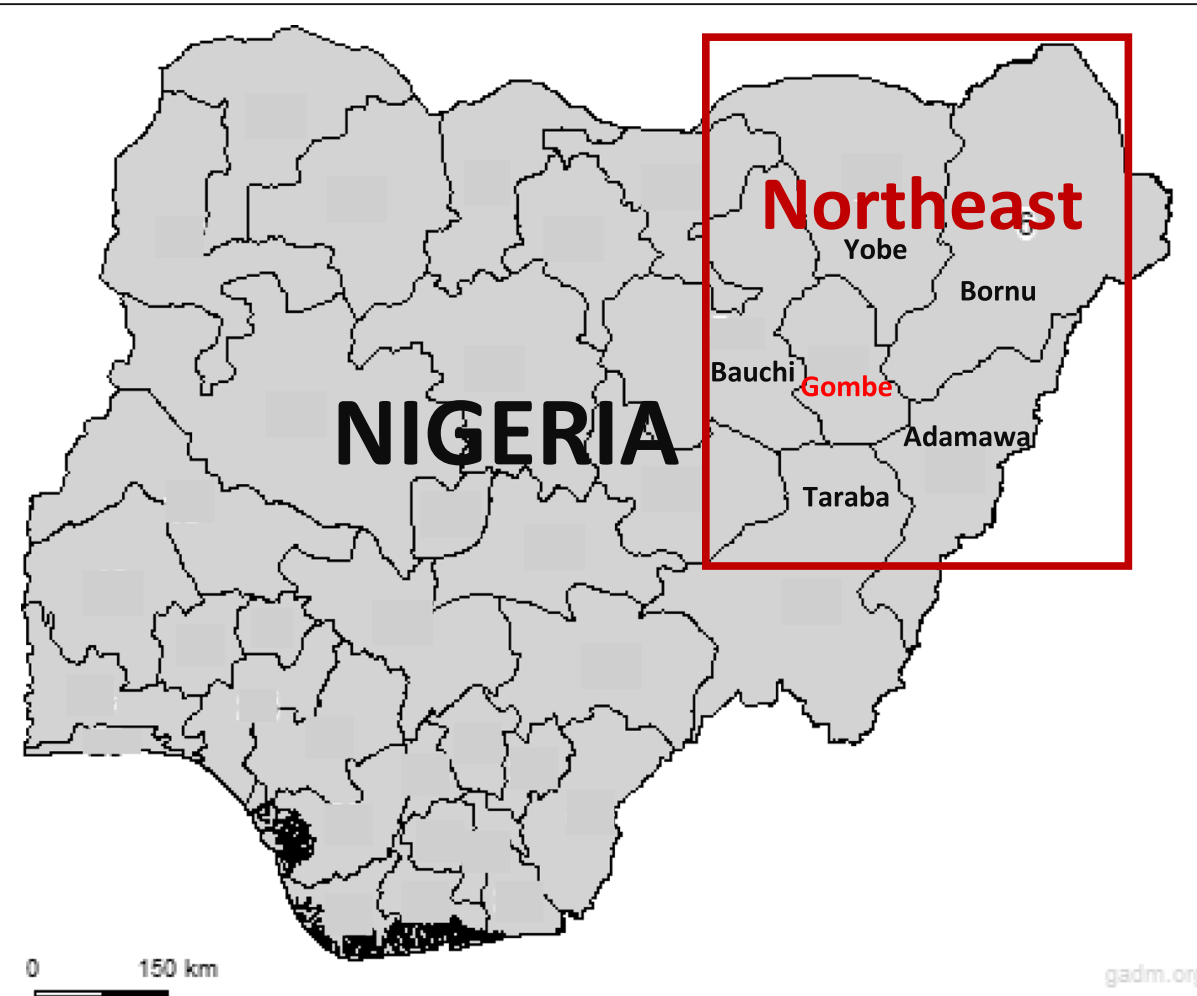

Fig. 1 Map of Nigeria showing northeast region and study area (Gombe State). Map source: adapted by authors based on data from GADM maps and data (https://gadm.org/index.html). GADM maps and data are freely available for academic and other non-commercial use

expulsion of the fetus at $\geq 28$ weeks of gestation (third trimester deaths) or with birth weight of $\geq 1000 \mathrm{~g}$ [14].

\section{Fresh stillbirths (FSB)}

Stillbirths in which the fetus was expelled with an intact skin suggesting that the death occurred during labour (Intrapartum) or less than $8 \mathrm{~h}$ before delivery. The categorisation as FSB was done by the attending doctors and nurses at the time of delivery.

\section{Macerated stillbirth (MSB)}

Any fetus expelled with signs of skin degeneration, suggesting the death have occurred before labour (antepartum) or more than $8 \mathrm{~h}$ before expulsion. The categorisation as MSB was done by the attending doctors and nurses at the time of delivery.

\section{Antepartum death}

In this study, antepartum death was defined as stillbirths whose mothers arrived at the healthcare facility before the onset of labour with absent fetal heart sound on examination or the delivery of a macerated stillbirth where the time of fetal demise is not known.

\section{Intrapartum death}

In this study, intrapartum death was defined as death of the fetus during labour in which the mother arrived with fetal heart sounds present and or the delivery of a fresh stillbirth where the time of fetal death is unknown.

\section{Booked pregnancy}

A booked pregnancy was defined as any pregnancy that was registered and or received antenatal care (ANC) in FTHG (as evidenced by the antenatal records) irrespective of the number of such ANC visits.

\section{Unbooked pregnancy}

This was any pregnancy that did not receive ANC at the FTHG but presented only during labour. Women who received ANC elsewhere were also classified as unbooked because their antenatal records were not available to the attending obstetrics team.

\section{Gestational age}

This was categorised according to the gestational weeks at delivery. This included; preterm $(28-<37$ weeks), term (37-42 weeks) and post term which was $>42$ weeks at delivery [15]. 


\section{Birth weight}

This was the measured weight of the stillborn at delivery. This was categorised into; Extreme low birth weight $(<1000 \mathrm{~g})$, very low birth weight (1000-1499), low birth weight (1500-2499 g) normal birth weight (2500-3999 g) and macrosomia which was birth weight $\geq 4000 \mathrm{~g}$ at delivery $[16,17]$.

\section{Application of ICD- PM classification system and assignment of cause of death}

The ICD 10-PM system classifies fetal causes of stillbirths based on the time of death as either Antepartum (designated as codes with prefix A) or Intrapartum (codes with prefix I), while maternal causes of perinatal mortality (including but not limited to stillbirths) are coded with the prefix M (Supplementary Table 1) [8]. The determination of the likely cause of death and classification of the stillbirth into the ICD-PM subcategories was independently carried out by two of the authors, ED and OE based on data from the maternal records. The final ICD-PM categories were arrived at by consensus and in cases where consensus is not reached, a third author was consulted. Due to the challenges with accurate dating of pregnancies, birth weight was used as a surrogate for gestational age as follows: fetuses $<2500$ g were coded under prematurity/ low birth weight/ growth restriction (A5/I6) $[8,18]$. However, prematurity/ low birth weight was only assigned as the cause of stillbirth when no other fetal cause was identified after an extensive review of the case and application of the ICDPM tool.

\section{Data analysis}

All statistical analyses were performed with Statistical Package for the Social Sciences (SPSS) (IBM, NY, version 24). The main outcome measures were the hospital-based Stillbirth Rate (SBR, stillbirths per 1000 births) and disaggregated causes of stillbirth based on ICD-PM classification system. We report SBR with accompanying 95\% confidence intervals (CI). Categorical and continuous variables are summarised respectively as proportions and means (standard deviations). Crosstabulations with the outcome were performed using the $X^{2}$ statistic for categorical variables, with statistical significance defined as alpha $<0.05$ (two-sided).

\section{Results}

Between 1 January 2010 and 31 December 2018 there were 21,462 deliveries (supplementary Table 2) at the Federal Teaching Hospital, Gombe, of which 1177 resulted in stillbirths giving an overall hospital SBR of 55 per 1000 births (95\% CI: 52, 58). The annual SBR ranged between 42 per 1000 births (95\% CI:34,51) and 65 per 1000 births (95\% CI: 55,76) during the period under review (Fig. 2), with an average annual reduction rate of about $2 \%$. There were two peaks in yearly stillbirths in 2012 and in 2015 (Fig. 2). Relevant maternal and fetal data needed for ICD-PM classification were available for all $760(65 \%)$ cases of the stillbirths retrieved for the period under review, and these cases were included in the descriptive analyses. The 35\% (417) of cases of stillbirths not included in the analysis were due to missing clinical notes and inability to retrieve maternal/foetal records which were all paper-based records.

\section{Background maternal and fetal characteristics}

Table 1 describes the maternal and fetal characteristics of the stillborn babies. The mean maternal age was 27.6 years (SD: 6.6) and did not differ $(p=0.294)$ between women who had experienced an antepartum stillbirth compared to those who had experienced an intrapartum stillbirth. The majority $(668 / 760 ; 87.9 \%)$ of women who experienced a stillbirth were aged 16-35 years. About four fifths $(625 / 760 ; 82.2 \%)$ of stillborn babies were delivered by women who did not receive ANC.

More than half $(384 / 760 ; 50.5 \%)$ of all stillborn babies weighed between 2500 and $3999 \mathrm{~g}$, but the mean birthweight of the intrapartum stillbirths was significantly heavier $(p=0.001)$ than that of the antepartum stillbirths (2642 $\mathrm{g}$ vs $2424 \mathrm{~g}$ ). Male and female stillborn babies were equally common ( $50.5 \%$ vs $49.5 \%$ respectively). Of the 760 stillbirths, $365(48 \%)$ were antepartum deaths, while 395 (52\%) were intrapartum.

\section{ICD-PM causes of stillbirths}

Maternal medical and surgical (M4) conditions were the most common (69.3\%) maternal cause of antepartum stillbirths (Table 2), while maternal complications of the placenta, cord and membranes (M1) were the most common (45.8\%) maternal cause of intrapartum stillbirth. In the M4 (maternal medical and surgical conditions) ICD-PM sub-category, the major clinical conditions included hypertensive disease in pregnancy (a spectrum including chronic hypertension, pregnancy induced hypertension, preeclampsia and eclampsia) and maternal severe anaemia which accounted for $69 \%$ (218/319) and 22\% (70/319) respectively (supplementary Table 3 ). The main clinical conditions in the M1 (complications of placenta, cord, etc.) ICD-PM sub-category included abruptio placenta [78.7\% $(166 / 211)]$, cord prolapse [9.5\% (20/211)] and placenta previa [9\% (19/211)].

Disorders related to fetal growth (A5), accounted for $56.7 \%$ of antenatal fetal causes of stillbirths in our study population, and were mostly associated with maternal medical (M4) conditions. Although the majority (45.1\%) of intrapartum stillbirths were categorised as fetal deaths of unspecified (I7) causes, those due to disorders related 


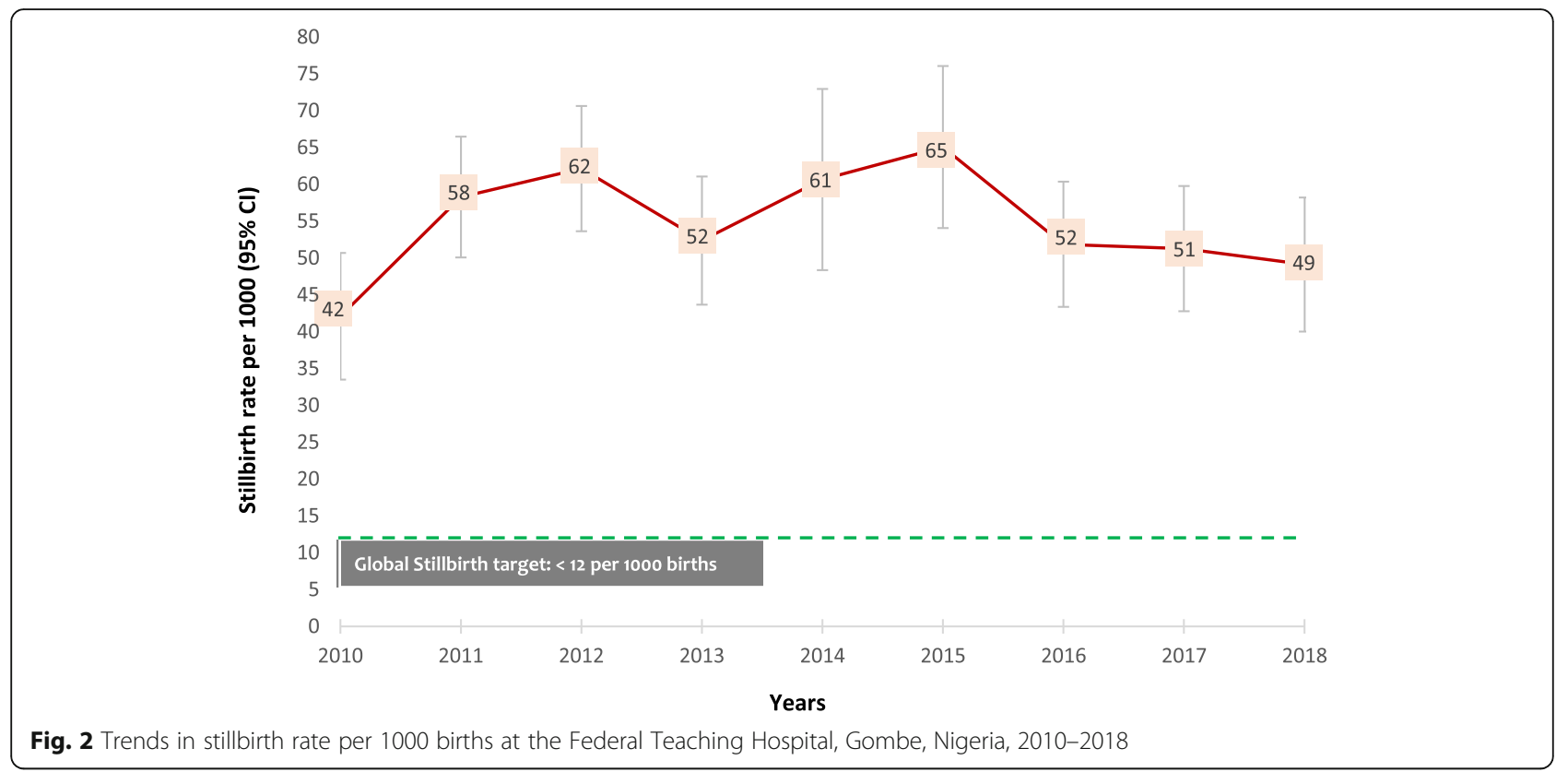

to fetal growth (I6) were mainly associated with maternal complications of placenta and cord (M1).

\section{Trends in ICD 10-PM causes of stillbirths, 2010-2018}

Maternal medical and surgical conditions (M4) followed by complications placenta and cord (M1) remained the highest maternal causes of stillbirth over the study period (Fig. 3a). This trend remained similar (i.e. both M1 and M4 were the most common maternal ICD-PM categories contributing to stillbirths) between 2010 and 2018, although with occasional dips. Overall, antepartum; disorder related to fetal growth (A5) and fetal death of unspecified cause (A6/I6) were the commonest fetal ICD-PM causes of stillbirth throughout, between 2010 and 2018 in our study setting (Fig. 3b).

\section{Discussion}

We have shown a consistently high burden of stillbirths in a major urban tertiary referral hospital in northeast Nigeria over a nine-year period between 2010 and 2018, with an SBR consistently above 4 times the ENAP national SBR target of 12/1000 births by 2030. Based on the ICD-PM, we identified maternal medical conditions and unspecified fetal disorders as the major causes of stillbirths. Comparable facility-based data from other regions in Nigeria are lacking; however, our reported facility-based SBR is higher than the national SBR of 42.9/1000 births [19]. Sub-Saharan Africa has the highest SBR and slowest rate of progress worldwide. Nigeria and Ethiopia are the two largest contributors to this stillbirth burden [1], but our reported SBRs are much lower than that reported from northern Ethiopia (85/1000 births) [20].
Before discussing our findings further, we acknowledge the following limitations of our study. First, our inability to retrieve case records (paper-based clinical notes) for $35 \%$ of the stillbirth cases identified during the period under review. This excluded a considerable number of stillbirth cases from our analysis and may have resulted in over- or under-estimation of the different causes of stillbirths. The difficulty in accessing health records and the challenge of poor record-keeping impede the collection of better data needed to save the lives of mothers and newborns in low income settings [21]. Second, is the variability in determining maceration based on fetal visual appearance by health professionals. The shortcoming of visual examination to assess degenerative skin changes in stillborn has been documented [22]. The health care providers who classified the stillbirths into fresh or macerated categories in this study were not specifically trained for this purpose but relied on their skills as midwives and doctors during routine clinical care. Third, due to the retrospective nature of our study, we are unable to determine the proportion of fetuses that were not systematically examined in the antepartum and intrapartum stillbirth categories. This limit, for example, the extent, to which our findings of a relatively nonexistence of congenital infection as a cause of stillbirth in our setting may be interpreted. However, we consider that our study is a critical initial step in unravelling broad categories of causes of stillbirths in a resourcelimited setting like ours. Lastly, the WHO ICD-PM classification system provides clinically relevant and easy-touse categorisation of the causes of stillbirths including time of stillbirth (ante- or intrapartum), assigns fetal and/or maternal contributory conditions. However, 
Table 1 Demographic and clinical characteristics of women who experienced a stillbirth and their stillborn babies at the Federal Teaching Hospital, Gombe, Nigeria, 2010-2018

\begin{tabular}{|c|c|c|c|c|c|}
\hline Variables & Categories & Antepartum $\boldsymbol{n}=365(\%)$ & Intrapartum $\boldsymbol{n}=395$ (\%) & $\begin{array}{l}\text { Total } \\
\boldsymbol{n}=760(\%)\end{array}$ & $P$ \\
\hline \multirow[t]{4}{*}{ Maternal Age (years) } & $<16$ & $2(0.5)$ & $1(0.3)$ & $3(0.4)$ & \\
\hline & $16-35$ & $315(86.3)$ & $353(89.4)$ & $668(87.9)$ & \\
\hline & $>35$ & $48(13.2)$ & $41(10.4)$ & $89(11.7)$ & 0.294 \\
\hline & Mean (SD) & $27.5(6.6)$ & $27.2(6.7)$ & $27.6(6.6)$ & 0.731 \\
\hline \multirow[t]{4}{*}{ Parity } & Nullipara (0) & $118(32.1)$ & $88(22.3)$ & $205(27.0)$ & \\
\hline & Primipara (1) & $37(10.2)$ & $47(11.9)$ & $84(11.1)$ & \\
\hline & Multipara (2-4) & $106(29.1)$ & $120(30.4)$ & $226(29.8)$ & \\
\hline & Grand multipara $(\geq 5)$ & $104(28.6)$ & $140(35.4)$ & $244(32.1)$ & 0.004 \\
\hline \multirow[t]{4}{*}{ Antenatal care } & No ANC & $280(76.7)$ & $345(87.3)$ & $625(82.2)$ & \\
\hline & $1-3$ visits & $54(14.8)$ & $29(7.4)$ & $83(10.9)$ & \\
\hline & $4-7$ visits & $30(8.2)$ & $17(4.3)$ & $47(6.2)$ & \\
\hline & $\geq 8$ & $1(0.3)$ & $4(1.0)$ & $5(0.7)$ & 0.001 \\
\hline \multirow[t]{2}{*}{ Type of pregnancy } & Singleton & $352(96.4)$ & $369(93.4)$ & $720(94.9)$ & \\
\hline & Multiple & $13(3.6)$ & $26(6.6)$ & $39(5.1)$ & 0.050 \\
\hline \multirow[t]{2}{*}{ Mode of delivery } & Vaginal $^{a}$ & $306(83.8)$ & $265(67.1)$ & $571(75.1)$ & \\
\hline & Caesarean section $^{\mathrm{b}}$ & $59(16.2)$ & $130(32.9)$ & $189(24.9)$ & $<0.001$ \\
\hline \multirow[t]{2}{*}{ Previous stillbirth } & No & $304(83.2)$ & $331(83.8)$ & $634(83.5)$ & \\
\hline & Yes & $61(16.8)$ & $64(16.2)$ & $125(16.5)$ & 0.845 \\
\hline \multirow[t]{9}{*}{ Year of stillbirth } & 2010 & $29(8.0)$ & $28(7.1)$ & $57(7.5)$ & \\
\hline & 2011 & $44(12.1)$ & $85(21.5)$ & $129(17.0)$ & \\
\hline & 2012 & $65(17.9)$ & $60(15.2)$ & $125(16.5)$ & \\
\hline & 2013 & $47(12.9)$ & $50(12.7)$ & $97(12.8)$ & \\
\hline & 2014 & $32(8.5)$ & $21(5.3)$ & $53(6.9)$ & \\
\hline & 2015 & $46(12.6)$ & $30(7.6)$ & $76(10.0)$ & \\
\hline & 2016 & $37(10.2)$ & $38(9.6)$ & $75(9.9)$ & \\
\hline & 2017 & $38(10.4)$ & $41(10.4)$ & $79(10.4)$ & \\
\hline & 2018 & $27(7.4)$ & $42(10.6)$ & $69(9.1)$ & 0.489 \\
\hline \multirow[t]{2}{*}{ Sex of Stillborn babies } & Female & $172(47.1)$ & $212(53.7)$ & $384(50.5)$ & \\
\hline & Male & $193(52.8)$ & $183(46.3)$ & $376(49.5)$ & 0.71 \\
\hline \multirow{7}{*}{$\begin{array}{l}\text { Birthweight (grams) } \\
\text { of stillborn babies }\end{array}$} & Extremely LBW $(<1000)$ & $16(4.4)$ & $10(2.5)$ & $26(3.4)$ & \\
\hline & Very LBW (1000-1499) & $42(11.5)$ & $30(7.6)$ & $72(9.5)$ & \\
\hline & Low birthweight (1500-2499) & $125(34.2)$ & $99(25.1)$ & $224(29.5)$ & \\
\hline & Normal birthweight (2500-3999) & $151(41.4)$ & $233(59.0)$ & $384(50.5)$ & \\
\hline & Macrosomia (> 4000) & $16(4.4)$ & $15(3.8)$ & $31(4.1)$ & \\
\hline & JMissing & $15(4.1)$ & $8(2.0)$ & $23(3.0)$ & $<0.001$ \\
\hline & Mean (SD) & $2424(962)$ & $2642(842)$ & $2540(907)$ & 0.001 \\
\hline \multirow{4}{*}{$\begin{array}{l}\text { Duration of } \\
\text { pregnancy (weeks) }\end{array}$} & Preterm (28-36) & $188(51.5)$ & $152(38.5)$ & $340(44.7)$ & \\
\hline & Term (37-41) & $136(37.3)$ & $183(46.3)$ & $319(42.0)$ & \\
\hline & Post term (42) & $24(6.6)$ & $14(3.5)$ & $38(5.0)$ & \\
\hline & JMissing & $17(4.6)$ & $46(11.7)$ & $63(8.3)$ & 0.001 \\
\hline
\end{tabular}

ancluded five (5) babies born via assisted (instrumental) vaginal deliveries

${ }^{\mathrm{b}}$ Included 51 babies delivered by laparotomy because their mothers had ruptured uterus 
Table 2 Application of the ICD-PM to determine causes of stillbirth at the Federal Teaching Hospital, Gombe, Nigeria, 2010-2018

\begin{tabular}{|c|c|c|c|c|c|c|}
\hline & $\begin{array}{l}\text { M1 } \\
\text { Complications of } \\
\text { placenta, cord, etc. }\end{array}$ & $\begin{array}{l}\text { M2 } \\
\text { Maternal } \\
\text { complications of } \\
\text { pregnancy }\end{array}$ & $\begin{array}{l}\text { M3 } \\
\text { other complications } \\
\text { of labour \& delivery }\end{array}$ & $\begin{array}{l}\text { M4 } \\
\text { Maternal medical \& } \\
\text { surgical conditions }\end{array}$ & $\begin{array}{l}\text { M5 } \\
\text { No } \\
\text { maternal } \\
\text { condition }\end{array}$ & $\begin{array}{l}\text { Total } \\
(\%)\end{array}$ \\
\hline \multicolumn{7}{|l|}{ Antepartum Death } \\
\hline $\begin{array}{l}\text { A1: Congenital malformations, } \\
\text { and chromosomal abnormalities }\end{array}$ & 0 & 7 & 0 & 2 & 2 & $\begin{array}{l}11 \\
(3.0)\end{array}$ \\
\hline A2: Infection & 0 & 0 & 0 & 1 & 0 & $1(0.3)$ \\
\hline A3: Antepartum hypoxia & 4 & 2 & 0 & 23 & 6 & $\begin{array}{l}35 \\
(9.6)\end{array}$ \\
\hline $\begin{array}{l}\text { A4: Other specified antepartum } \\
\text { disorder }\end{array}$ & 0 & 1 & 0 & 0 & 0 & $1(0.3)$ \\
\hline $\begin{array}{l}\text { A5: Disorder related to fetal } \\
\text { growth }\end{array}$ & 22 & 11 & 0 & 144 & 30 & $\begin{array}{l}206 \\
(56.7)\end{array}$ \\
\hline $\begin{array}{l}\text { A6: Antepartum death of } \\
\text { unspecified cause }\end{array}$ & 4 & 6 & 0 & 83 & 17 & $\begin{array}{l}110 \\
(30.1)\end{array}$ \\
\hline Total $n=(\%)$ & $30(8.2)$ & $27(7.4)$ & $0(0.0)$ & $253(69.3)$ & $55(15.1)$ & $\begin{array}{l}365 \\
(100.0)\end{array}$ \\
\hline \multicolumn{7}{|l|}{ Intrapartum Death } \\
\hline $\begin{array}{l}\text { I1: Congenital malformations, } \\
\text { and chromosomal abnormalities }\end{array}$ & 1 & 7 & 8 & 3 & 1 & $\begin{array}{l}20 \\
(5.1)\end{array}$ \\
\hline I2: Birth trauma & 0 & 0 & 0 & 0 & 0 & $0(0.0)$ \\
\hline I3: Acute intrapartum event & 10 & 3 & 17 & 8 & 3 & $\begin{array}{l}41 \\
(10.3)\end{array}$ \\
\hline 14: Infection & 0 & 0 & 0 & 0 & 0 & $0(0.0)$ \\
\hline $\begin{array}{l}\text { 15: Other specified intrapartum } \\
\text { event }\end{array}$ & 0 & 0 & 0 & 0 & 0 & $0(0.0)$ \\
\hline $\begin{array}{l}\text { 16: Disorder related to fetal } \\
\text { growth }\end{array}$ & 87 & 7 & 26 & 31 & 5 & $\begin{array}{l}156 \\
(39.5)\end{array}$ \\
\hline $\begin{array}{l}\text { 17: Intrapartum of unspecified } \\
\text { cause }\end{array}$ & 83 & 3 & 61 & 24 & 7 & $\begin{array}{l}178 \\
(45.1)\end{array}$ \\
\hline Total $\mathbf{n}=(\%)$ & $181(45.8)$ & $20(5.1)$ & $112(28.3)$ & $66(16.7)$ & $16(4.1)$ & $\begin{array}{l}395 \\
(100.0)\end{array}$ \\
\hline Grand Total $\mathbf{N}=(\%)$ & $211(27.8)$ & $47(6.2)$ & $112(14.7)$ & 319 (41.9) & $71(9.4)$ & $\begin{array}{l}760 \\
(100.0)\end{array}$ \\
\hline
\end{tabular}
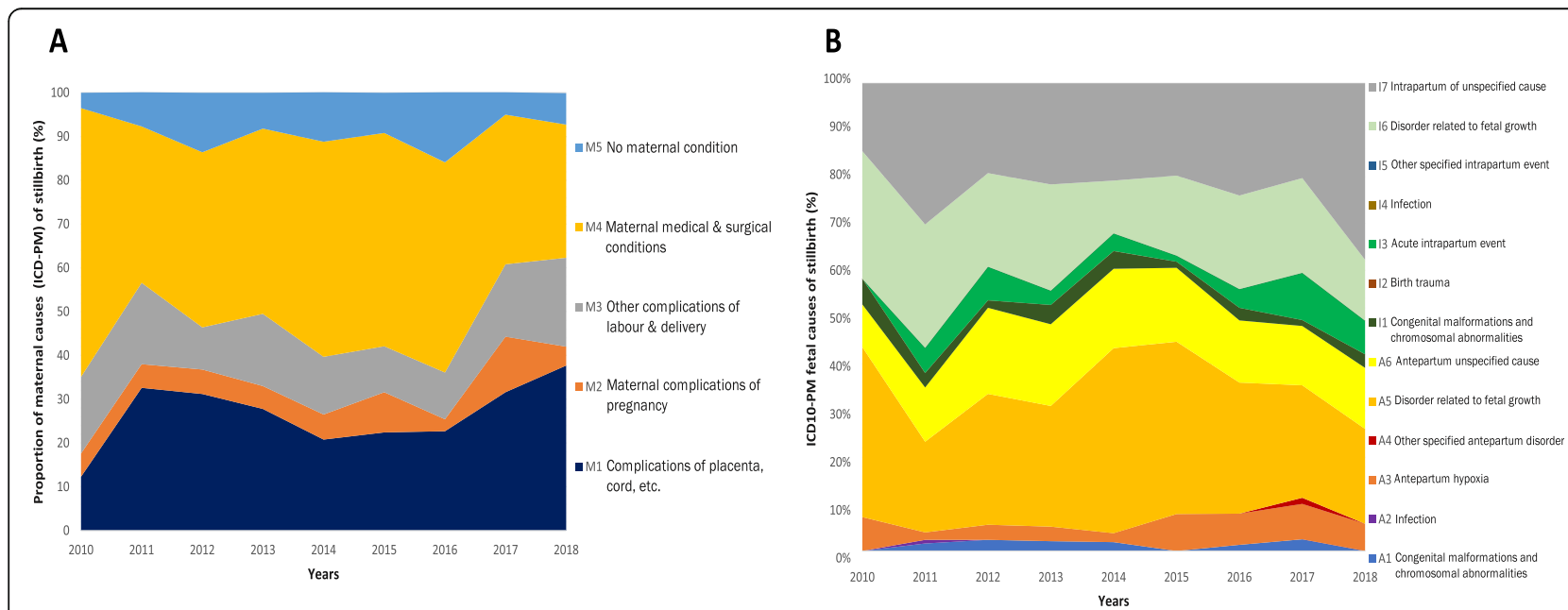

Fig. 3 Trends in the contribution of (a) maternal causes and (b) fetal causes (ICD-PM) to stillbirths at the Federal Teaching Hospital, Gombe, Nigeria, 2010-2018 
other classification systems that examine care-related factors alongside fetal and maternal contributory factors exist and may enhance the identification of prevention priorities at the macro- and meso-levels of the health system [10].

There were two peaks in stillbirth (in 2012 and 2015) in our study. Although Gombe (our study setting) is in the northeast of Nigeria, it was considered a "non-conflict state", i.e. a State with a low intensity of BokoHaram attacks [12]. This unique characteristic made FTHG (the study setting) relatively safer and functional and it served as the major tertiary-level referral centre for maternal health services from surrounding States in northeast Nigeria. Thus, there might have been an increased migration of people and referral of women with complicated pregnancies from "conflict affected" (i.e. States with high intensity of Boko Haram attacks) states in northeast Nigeria to Gombe in 2012 and 2015, which coincided with peaks in stillbirth rates. However, the data on the intensity of armed conflicts in northeast Nigeria between 2009 and 2018 did not suggest substantially higher intensity of Boko Haram attacks in 2012 and 2015 in the "conflict affected" areas [23].

Beginning from 2015, a slight annual reduction in the SBR of about $2 \%$ was observed, but this is considerably lower than the $4.2 \%$ reduction rate recommended to achieve the ENAP target of $<12$ deaths per 1000 livebirths by 2030 [1]. At the current rate of decline, the 2030 target will not be met, and it will take decades at the present rate of progress before the average pregnant women has the same chance of having a live birth as does a woman nowadays in a high-income country [1]. A monumental shift in SBR reduction is therefore required to get on-track. One reason for the observed slow decline in the SBR may be the armed conflict affecting parts of northeast Nigeria which has negatively impacted the utilisation of health services such as ANC and facility-based delivery, and hampered programmatic efforts aimed at delivering improved health services [6]. Stillbirths are strongly linked to adverse social and economic determinants of health. In a region of Nigeria with an already significantly high burden of maternal, perinatal, infant and childhood mortality [24], failure to address the impact of the complex political, socioeconomic and security issues on health coverage will widen equity gaps between regions and make it impossible for Nigeria to make progress without leaving anyone behind.

Based on the time of death, M4 (maternal medical and surgical) conditions caused more antepartum death while M1 (disorders of placenta, cord and membranes) conditions resulted in more intrapartum deaths. This result differs from that of Aminu et al. [11] also based in west Africa, where M1 (disorders of placenta, cord and membranes) and M3 (intrapartum complications) conditions were the most frequent maternal causes of stillbirth in the antepartum and intrapartum periods respectively. A plausible explanation for our finding is that maternal medical conditions like hypertensive disorders in pregnancy, diabetes mellitus and anaemia are more likely to cause fetal demise before the onset of labour. In contrast, intrapartum complications such as abruptio placentae and cord prolapse (M1), and obstructed labour (M3) causes intrapartum death. Although the study by Aminu et al. was prospective, there were methodological similarities with our study in the assignment of cause and time of fetal death. Despite contact with a health system before, during and after pregnancy, many women and their newborns do not receive high quality care. Ensuring high quality ANC will enable early detection and treatment of maternal medical conditions. Immediate access to emergency obstetric services when complications occur is crucial to the survival of mother and child, and can provide effective interventions to prevent or treat placenta and intrapartum complications [11].

The predominant antepartum and intrapartum fetal causes of stillbirth were prematurity/growth disorders (A5/I6). This finding contrasts data from a previous study by Aminu et al. [11] where congenital infections (A2) and acute intrapartum events (I3) constituted the majority of antepartum and intrapartum causes respectively. In contrast to the 'unidentified' maternal conditions (M5) which constituted a small proportion of the maternal causes of stillbirth in our setting, 'unspecified' ante- and intrapartum fetal conditions (A6/I7) made up a significant proportion of fetal causes of stillbirth. We believe this is due to the lack of systematic fetal examination after the delivery of a stillborn [25]. As is the case in most sub-Saharan African settings, the routine examination of stillborn infants at the FTHG consists of weight measurement and gross general examination without an accurate estimation of gestational age. Furthermore, the non-performance of autopsies, histopathological examination of placenta tissues and serological studies, hinders the definitive diagnoses of congenital infections such as Syphilis and Malaria (A2 \& I4) which may constitute a significant group in the aetiology of stillbirths [26]. Autopsies, placenta tissue histology and fetal serological studies are not routinely performed in many LMICs [25]. In their study on causes of stillbirths in South Africa, Madhi et al. [27] performed histologic analysis of placenta and fetal blood culture, and found congenital infections as responsible for $19 \%$ of stillbirths. Future prospective studies in our setting exploring the contribution of infection to stillbirths using methods similar to those deployed by Madhi et al. [27] in South Africa will be warranted to provide much needed 
aetiological information which is lacking but necessary to prevent future deaths, improve the quality of care and guide resource allocation.

\section{Conclusions}

Our study provides trend data and useful insights on the causes of stillbirth in the northeast region of Nigeria. Unless present SBR trends change, equity gaps between regions in Nigeria, particularly conflict-stricken areas, continue to widen over time. Most stillbirths, especially intrapartum stillbirths, are preventable; however, accelerating progress to end preventable stillbirths requires improved data which in turn requires improvements in hospital and national information systems. Such data will strengthen accountability for evidenced-based effective interventions.

\section{Supplementary information}

Supplementary information accompanies this paper at https://doi.org/10. 1186/s12884-020-03059-8.

Additional file 1: Table S1. WHO ICD-PM stillbirth classification. Table S2. Summary of births, stillbirths, stillbirth rates and stillbirth cases retrieved per years at the Federal Teaching Hospital, Gombe, Nigeria, 20102018. Table S3. Summary of major clinical conditions under the ICD-PM sub-categories at the Federal Teaching Hospital, Gombe, Nigeria, 20102018.

\section{Abbreviations}

ANC: Antenatal Care; ENAP: Every Newborn Action Plan; FTHG: Federal Teaching Hospital Gombe; GBD: Global Burden of Diseases; ICDPM: International Classification of Disease (10th Revision)- Perinatal Mortality; LMICS: Low-and Middle-Income Countries; MDG: Millennium Development Goals; SBR: Stillbirth Rate; SDG: Sustainable Development Goals;

UNICEF: United Nations Children's Fund; WHO: World Health Organization

\section{Acknowledgements}

The authors wish to acknowledge the labour ward manager, Balkisu Mamman and staff of the Medical Records Department of FTHG for their immense help in retrieving the records of stillbirth cases used for this study.

\section{Authors' contributions}

ED: conceived of the study together with OW, OE and JAKA, abstracted the data, assigned ICD-PM causes of stillbirth, contributed to data analysis, prepared the first draft of the manuscript and critically reviewed all drafts of the manuscript. OW: Led data analysis, prepared the first draft of the manuscript and critically reviewed all drafts of the manuscript. OE: abstracted the data, assigned ICD-PM causes of stillbirth, contributed to data analysis, prepared the first draft of the manuscript and critically reviewed all drafts of the manuscript. JAKA: contributed to data analysis, prepared the first draft of the manuscript and critically reviewed all drafts of the manuscript. IJ supervised the study design and data analysis, and critically reviewed all drafts of the manuscript. NM, UO and AUE supervised the study design, data analysis, interpretation of results, and critically reviewed all drafts of the manuscript. All authors have read and approved the manuscript.

\section{Funding}

There was no external funding for this study.

\section{Ethics approval and consent to participate}

This study was approved by the Research and Ethics Committee of the Federal Teaching Hospital Gombe (NHREC/25/10/2013). Due to the retrospective nature of this analysis and the fact that the data was part of routine clinical care, informed consent for participants included was waived by the ethics committee on condition that all data were anonymized.

\section{Consent for publication}

Not applicable.

\section{Competing interests}

None declared.

\section{Author details}

${ }^{1}$ Department of Obstetrics and Gynaecology, Federal Teaching Hospital Gombe, Gombe, Nigeria. ${ }^{2}$ African Population and Health Policy Initiative, Gombe, Gombe State, Nigeria. ${ }^{3}$ Vaccines and Immunity Theme, Medical Research Council (MRC) Unit The Gambia at The London School of Hygiene and Tropical Medicine, Banjul, The Gambia. ${ }^{4}$ Aberdeen Centre for Health Data Science (ACHDS), Institute of Applied Health Sciences, University of Aberdeen, Aberdeen, UK. ${ }^{5}$ Department of Community Health and Epidemiology, College of Medicine, University of Saskatchewan, Saskatoon, Canada. ${ }^{6}$ Department of Paediatrics, Federal Teaching Hospital Gombe, Gombe, Nigeria. ${ }^{7}$ Department of Paediatrics, College of Medical Sciences, Gombe State University, Gombe, Nigeria. ${ }^{8}$ Department of Obstetrics and Gynaecology, College of Medical Sciences, Gombe State University, Gombe, Nigeria.

Received: 28 August 2019 Accepted: 16 June 2020

Published online: 01 July 2020

\section{References}

1. Lawn JE, Blencowe H, Waiswa P, Amouzou A, Mathers C, Hogan D, et al. Stillbirths: rates, risk factors, and acceleration towards 2030. Lancet. 2016; 387(10018):587-603.

2. Blencowe H, Cousens S, Jassir FB, Say L, Chou D, Mathers C, et al. National, regional, and worldwide estimates of stillbirth rates in 2015, with trends from 2000 : a systematic analysis. Lancet Glob Heal. 2015;4(2):e98-108.

3. WHO, UNICEF. Every newborn: an action plan to end preventable deaths. Geneva: WHO; 2014

4. Horton R, Samarasekera U. Stillbirths : ending an epidemic of grief. Lancet. 2016:387(10018):515-6.

5. The National Bureau of Statistics. NIGERIA: Sustainable Development Goals (SDGs) Indicators Baseline Report 2016. 2017.

6. Chukwuma A, Ekhator-mobayode UE. Armed conflict and maternal health care utilization : evidence from the Boko haram insurgency in Nigeria. Soc Sci Med. 2019;226:104-12.

7. Frøen JF, Gordijn SJ, Abdel-aleem H, Bergsjø P, Betran A, Duke CW, et al. Making stillbirths count, making numbers talk - issues in data collection for stillbirths. BMC Pregnancy Childbirth. 2009;9:58.

8. World Health Organization. The WHO application of ICD-10 to deaths during the perinatal period: ICD-PM. Geneva: World Health Organization; 2016.

9. Allanson ER, Tunçalp Ö, Gardosi J, Pattinson RC, Francis A, Vogel JP, et al. The WHO application of ICD-10 to deaths during the perinatal period (ICDPM): results from pilot database testing in South Africa and United Kingdom. BJOG An Int J Obstet Gynaecol. 2016;123(12):2019-28.

10. Lavin T, Allanson ER, Nedkoff L, Preen B, Pattinson RC. Applying the international classification of diseases to perinatal mortality data, South Africa. Bull World Health Organ. 2018;96:806-16.

11. Aminu M, Mathai $M$, van den Broek N. Application of the ICD-PM classification to stillbirth in four sub-Saharan African countries. PLoS One. 2019;14(5):e0215864

12. Dunn G. The impact of the Boko Haram insurgency in Northeast Nigeria on childhood wasting: a double-difference study. Confl Health. 2018;12:6.

13. National Bureau of Statistics. Demographic statistics bulletin. Abuja: National Bureau of Statistics; 2018.

14. Lawn JE, Gravett MG, Nunes TM, Rubens CE, Stanton C. Global report on preterm birth and stillbirth (1 of 7): definitions, description of the burden and opportunities to improve data. BMC Pregnancy Childbirth. 2010;10(1):1. 
15. Blencowe H, Cousens S, Chou D, Oestergaard M, Say L, Moller A, et al. Born too soon: the global epidemiology of 15 million preterm births. Reprod Health. 2013;10(Suppl 1):1-14.

16. Cutland CL, Lackritz EM, Mallett-Moore T, Bardají A, Chandrasekaran R, Lahariya C, et al. Low birth weight: case definition \& guidelines for data collection, analysis, and presentation of maternal immunization safety data. Vaccine. 2017;35(48):6492-500.

17. Biratu AK, Wakgari N, Jikamo B. Magnitude of fetal macrosomia and its associated factors at public health institutions of Hawassa city, southern Ethiopia. BMC Res Notes. 2018;11(1):1-6.

18. Kramer MS, Platt RW, Wen SW, Joseph KS, Allen A, Abrahamowicz M. A new and improved population-based Canadian reference for birth weight for gestational age. Paediatrics. 2001;108(2):e35.

19. Blencowe H, Cousens S, Jassir FB, Say L, Chou D, Mathers C. National, regional, and worldwide estimates of stillbirth rates in 2015, with trends from 2000: a systematic analysis. Lancet Glob Heal. 2016;4:e98-108.

20. Lakew D, Tesfaye D, Mekonnen H. Determinants of stillbirth among women deliveries at Amhara region, Ethiopia. BMC Pregnancy Childbirth. 2017;17(1):1-7.

21. Pirkle CM, Dumont A, Zunzunegui MV. Medical recordkeeping, essential but overlooked aspect of quality of care in resource-limited settings. Int I Qual Health Care. 2012;24(6):564-7. https://doi.org/10.1093/intghc/mzs034.

22. Gold KJ, Abdul-Mumin A-RS, Boggs ME, Opare-Addo HS, Lieberman RW. Assessment of "fresh" versus "macerated" as accurate markers of time since intrauterine fetal demise in low-income countries. Int J Gynecol Obstet. 2014;125(3):223-7.

23. Uppsala Conflict Data Program. UCDP - Uppsala Conflict Data Program. Available from: https://ucdp.uu.se/exploratory. Accessed 15 May 2020.

24. National Population Commission (NPC) [Nigeria] and ICF International. Nigeria Demographic and Health Survey 2013. Abuja, Rockville: NPC and ICF International; 2014.

25. Goldenberg RL, Muhe L, Saleem S, Dhaded S, Goudar SS, Patterson J, et al. Criteria for assigning cause of death for stillbirths and neonatal deaths in research studies in low- middle income countries. J Matern Neonatal Med. 2019;32(11):1915-23.

26. Goldenberg RL, McClure EM, Saleem S, Reddy UM. Infection-related stillbirths. Lancet. 2010;375(9724):1482-90.

27. Madhi SA, Briner C, Maswime S, Mose S, Mlandu P, Chawana R, et al. Causes of stillbirths among women from South Africa: a prospective, observational study. Lancet Glob Heal. 2019;7(4):e503-12.

\section{Publisher's Note}

Springer Nature remains neutral with regard to jurisdictional claims in published maps and institutional affiliations.

Ready to submit your research? Choose BMC and benefit from:

- fast, convenient online submission

- thorough peer review by experienced researchers in your field

- rapid publication on acceptance

- support for research data, including large and complex data types

- gold Open Access which fosters wider collaboration and increased citations

- maximum visibility for your research: over $100 \mathrm{M}$ website views per year

At $\mathrm{BMC}$, research is always in progress.

Learn more biomedcentral.com/submissions 